\title{
Grounding, Essence, and Contingentism
}

\author{
Karol Lenart ${ }^{1}$
}

Received: 20 October 2019 / Revised: 6 March 2021 / Accepted: 10 March 2021 /

Published online: 8 April 2021

(c) The Author(s) 2021

\begin{abstract}
According to grounding necessitarianism if some facts ground another fact, then the obtaining of the former necessitates the latter. Proponents of grounding contingentism argue against this claim, stating that it is possible for the former facts to obtain without necessitating the latter. In this article I discuss a recent argument from restricted accidental generalisations provided by contingentists that advances such possibility. I argue that grounding necessitarianism can be defended against it. To achieve this aim, I postulate a relationship between grounding and essence by introducing a notion of individual essences understood as a set of essential properties that individuate its bearer. According to a proposed view grounding holds in virtue of identities of its relata, which are in turn determined by their respective individual essences. From there I claim that if grounding holds in virtue of the individual essences of its relata, then it is possible to resist the objection from restricted accidental generalisations and maintain a view that grounds necessitates what is grounded.
\end{abstract}

Keywords Grounding · Dependence $\cdot$ Necessity $\cdot$ Contingency $\cdot$ Essence $\cdot$ Facts

\section{Introduction}

Grounding necessitarianism is a view according to which a ground necessitates what is grounded (Audi, 2012; Correia, 2005; Dasgupta, 2014a, b; deRosset, 2013a; Fine, 2012). Grounding contingentism, on the other hand, is a denial of grounding necessitarianism (Chudnoff, manuscript; Dancy, 2004; deRosset, 2013b; Leuenberger, 2014; Skiles, 2015; Schnieder, 2016). According to this view, it is possible for grounds to obtain without necessitating what is grounded. Grounding contingentism has been recently advanced by argument from so-called "restricted accidental generalisations" (Carnino, 2015; Chudnoff, manuscript; Skiles, 2015; McDaniel, 2017). In this article, I provide a way of defending grounding necessitarianism against the

Karol Lenart

karol.lenart@doctoral.uj.edu.pl

1 Department of Philosophy, Jagiellonian University, Krakow, Poland 
argument from restricted accidental generalisations. A view that I propose appeals to the notion of essence and its relation to grounding. However, my approach is novel in its introduction of individual essence, which has to be distinguished from the notions of nature or generic/kind essence. I then argue that grounding holds (with necessity) in virtue of the individual essences of its both relata. If that is correct, then grounding necessitarianism can be defended against the argument from restricted accidental generalisations. However, a successful defence against the argument from restricted accidental generalisations does not protect grounding necessitarianism from other issues. Thus, the aim of this paper is modest. I focus merely on that how a proponent of grounding necessitarianism could convincingly respond to the argument from restricted accidental generalisations.

Before I start let me make some preliminary assumptions:

For the purpose of the analysis I follow a quite common understanding of grounding (which remains neutral regarding the debate between grounding necessitarianism and contingentism) according to which grounding is a relation (not a sentential operator ${ }^{1}$ ) that holds between facts (Leuenberger, 2014; Rosen, 2010; Skiles, 2015; Trogdon, 2013a) which are conceived as true structured propositions (King, 2007, 2009; Soames, 2010). ${ }^{2}$ Additionally, I assume that grounding is plural on the left side and singular on the right side. I use a standard schema for grounding relationships:

\section{Grounding: $[\Phi]$ grounds $[f]$}

I use square brackets to form names for facts. Fact $[\Phi]$ is a plurality of facts that ground a single derivative fact $[f]$.

Lastly, full grounding is the main topic and focus of this article. I have decided to set aside partial grounding, as contingentism is trivially true about partial grounding (Skiles, 2015: 721). If [Ф] fully grounds $[f]$, then $[\Phi]$ is a necessary and sufficient condition for $[f]$. However, if $[\Phi]$ only partially grounds $[f]$, then $[\Phi]$ is a necessary but insufficient condition for $[f]$. Thus, partial grounding provides a premise for cases in which all facts mentioned in $[\Phi]$ obtain but not $[f]$. Thus, if grounding necessitarianism is true at all, it holds only for full grounding.

The plan of my article is as follows: In section two, I reconstruct the argument from restricted accidental generalisations. Next, in section three I characterise grounding necessitarianism and its relation to essence. Here I also introduce a notion of individual essence and investigate its relationship to grounding. The link between grounding and individual essence is used in section four to tackle the argument from restricted accidental generalisations. In section five I provide responses to some possible objections to my proposal. I conclude in section six.

\footnotetext{
1 There is a wide discussion about whether grounding is a relation or sentential operator. For a general overview, see Correia (2013); Raven (2015); and Trogdon (2013b). It is important to note that my defence of necessitarianism is applicable for a relational understanding of grounding. At this point I remain agnostic whether it applies to the alternative conceptions of grounding.

2 That said, arguments provided in this article might be reconstructed within alternative theories of facts, at least as long as such theories would postulate that facts are individuated by their constituents. It will become clear in section three of this article why such a requirement is important.
} 


\section{Argument from Restricted Accidental Generalisations}

In arguing against grounding necessitarianism, contingentists rely on the following common and intuitive understanding of grounding necessitarianism:

Grounding necessitarianism: If $[\Phi]$ grounds $[f]$, and if $[\Phi]$ obtains, then $[\Phi]$ necessitates [f] (Rosen, 2010; Trogdon, 2013a; Leuenberger, 2014; Skiles, 2015).

According to such view, if $[\Phi]$ grounds $[f]$ and $[\Phi]$ obtains, then $[f]$ is metaphysically entailed by $[\Phi]$. Usually, contingentists deny grounding necessitarianism by showing possible scenarios according to which [ $\Phi]$ obtains but does not entail $[f]$. Below I would like to focus on a specific kind of such a scenario that invokes the notion of restricted accidental generalisations. Such scenarios were recently suggested by Alexander Skiles (2015) and Chudnoff (manuscript). In what follows I will rely on Skiles's characterisation of the argument because it is at once more general and more detailed than its alternatives.

Skiles's argument against grounding necessitarianism relies on a special kind of a general fact called restricted accidental generalization. For Skiles, a general fact is a fact that has the simplest logical form: $[\forall x \Phi]$, where " $\Phi$ " is an open formula in which $x$ occurs unbound; for example, [ $\forall x(x$ is white swan)] (Skiles, 2015: 729). These facts are general because they involve a universal quantifier and thus, in principle, are applicable to the more than one entity. We could label such facts as unrestricted general facts. However, among general facts there are also restricted general facts, which are focused on some particular domain of $x \mathrm{~s}$, but not all of them. The simplest logical form of such a fact is $[\forall x(F x \rightarrow G x)]$. For example, $[\forall x(x$ is swan in Switzerland $\rightarrow x$ is white $)]$. Skiles observes that some restricted general facts $[\forall x(F x \rightarrow G x)]$ are restricted accidental generalisations. According to Skiles, a restricted accidental generalisation is a restricted general fact iff it obtains in the actual world, $w_{@}$, but fails to obtain in another possible world, $w_{x}$. Here, world $w_{x}$ is assumed to have the same laws of nature as $w_{@}$. Skiles argues that if restricted accidental generalisations are grounded, they provide the strongest argument against grounding necessitarianism. The argument runs as follows:

Suppose that the following restricted accidental generalisation is true:

(1) $[\forall x(x$ is a swan in Switzerland $\rightarrow x$ is white $)]$.

Let's call this fact $[p]$.

Skiles then assumes an obvious natural principle that specifies what grounds every restricted accidental generalisation:

(2) Restricted accidental generalisations are fully grounded in their instances.

For the sake of the argument, assume that there are the only three swans in Switzerland: $a_{1}, a_{2}$, and $a_{3}$. Given this assumption, plausible grounds for (1) are the following:

(3) $\left[a_{1}\right.$ is a white swan in Switzerland], [ $a_{2}$ is a white swan in Switzerland], [ $a_{3}$ is a white swan in Switzerland]. 
Each of these facts could be called $\left[a_{1}\right],\left[a_{2}\right],\left[a_{3}\right]$, respectively. This represents a plurality of facts that grounds a single derivative fact $[p]$. Yet, in order to simplify my later investigations, I will use $[Q]$ as a name for a single conjunctive fact according to which $\left[a_{1} \& a_{2} \& a_{3}\right]$. Using these simplifications, we can state that:

(4) $[Q]$ grounds $[p]$.

Contingentists claim that even though (4) is an example of grounding, it is not a case of metaphysical necessitation. After all, there is a possible world, $w_{x}$, obeying the same laws of nature as the actual world $w_{@}$ does, in which a black swan was smuggled into Switzerland from Poland. Call such a swan $a_{4}$ and call the fact that $a_{4}$ is a black swan in Switzerland $\left[a_{4}\right]$. Next, assume that $a_{1}, \ldots a_{4}$ are all the swans in Switzerland. Then, we receive, distinct from $[Q]$, conjunctive fact $\left[Q^{*}\right]$, according to which:

(5) $\left[a_{1}\right.$ is a white swan in Switzerland \& $a_{2}$ is a white swan in Switzerland \& $a_{3}$ is a white swan in Switzerland \& $a_{4}$ is a black swan in Switzerland].

Following this, Skiles argues that even though [Q] obtains at $\mathrm{w}_{\mathrm{x}}$, [Q] does not entail [p] at $\mathrm{w}_{\mathrm{x}}$ because there is an additional swan, $\mathrm{a}_{4}$, that makes fact [p] absent at $\mathrm{w}_{\mathrm{x}}$. That is, it is not the case in $\mathrm{w}_{\mathrm{x}}$ that all swans in Switzerland are white. As a result, grounding necessitarianism is false.

\section{Grounding Necessitarianism and Essences}

I argue that grounding necessitarianism can be defended against the argument presented above. To support this claim, I appeal to a view that grounding holds in virtue of the essences of its relata. Many philosophers have argued that there is a close connection between the notions of grounding and of essence (Dasgupta, 2014b; Fine, 2012, 2015; Rosen, 2010; Trogdon, 2013a). The most general idea lying behind such connection might be expressed as follows:

Ground-essence link: If $[\Phi]$ grounds $[p]$, then $[\Phi]$ grounds $[p]$ in virtue of the essence of $[\Phi],[p]$, or both. ${ }^{3}$

It is important to note that even though ground-essence link imposes a necessary condition on grounding, it is not sufficient for it. This partially explains the irreducibility of grounding to essence. By accepting the ground-essence link, I intend to preserve the integrity of both by not reducing either of them. Indeed, I am of the opinion (following Fine, 2012) that we need both concepts to do metaphysics. This entails that essence is also irreducible to any other metaphysical concept. ${ }^{4}$

\footnotetext{
3 At this point I do not want to prejudge whether essences of both relata (essence of grounding base or essence of derivative fact) are sufficient for establishing grounds for grounding itself. I will come back to this issue in a moment.

4 Recently, there have been attempts to reduce both grounding and essence to a generalized identity (Correia \& Skiles, 2019). I do not follow this approach.
} 
By appealing to essences, one can explain at least three important features usually associated with grounding. Firstly, one can provide explanatory power for grounding explanations. In the most general perspective, to describe the essence of entity $e$ implies providing an explanation of what being entity $e$ entails. Therefore, if grounding holds in virtue of the essences of its relata, it involves the explanatory power of an essentialist description of its relata. Secondly, one can appeal to essences in order to explain by virtue of what a given instance of grounding relation holds. ${ }^{5}$ If one agrees with the premises that all grounding relations are grounded and that these grounds are further grounded, then grounds for initial grounding relations are ultimately not established: they are "infinitely deferred, never achieved" (Schaffer, 2010: 62). Given that essences are fundamental, i.e., ungrounded, (this is a common assumption about essences), one can maintain that essences provide ultimate grounds for grounding and, thus, stop the regress concerning grounds for grounding identified by Schaffer. ${ }^{6}$ Thirdly, and most importantly, the ground-essence link can provide a metaphysical explanation of the fact that grounding holds with necessity (Carnino, 2015; Trogdon, 2013a). The reason is straightforward: essences are necessary elements of being (even though, as Fine (1994) has shown, essence is irreducible to necessity), so it follows that if grounding holds in virtue of the essences of its relata, then grounding holds with necessity. In what follows I will focus solely on the third issue.

As I have indicated already, I am not the first to claim that the necessary status of grounding can be defended through appeal to essences. However, what is new about my approach is my argument that grounding relations hold in virtue of the individual essences of their relata. The main motivation for my view is that it explains the necessary status of grounding solely in virtue of identity conditions of its relata (i.e., facts). As a result, my approach can be successful without an appeal to natures or generic (kind) essences of entities involved in the relata of grounding (e.g., essence of humanity, nature of Socrates) and relations between such essences. ${ }^{7}$ Thus, if my argument succeeds, it provides a new way of answering the objection from restricted accidental generalisations that can avoid issues associated with the standard essentialist explanations of grounding based on the notion of generic essence.

Before I explain my view, the notion of individual essence needs to be defined. According to the most common understanding, individual essence is a collection of essential properties that are necessary (if individual $\alpha$ has individual essence $\Psi$,

\footnotetext{
5 It is worth noting that appeal to essences is not the only means of providing grounds for grounding. For some alternative approaches see: (Dixon, 2016; Rabin \& Rabern, 2016).

6 One might argue against Schaffer's remark and claim that infinite regress concerning grounds for grounding does not contradict the well-foundedness of grounding (Bennett, 2011; Rabin \& Rabern, 2016). Even if that is the case, I maintain that it is best to avoid infinite regresses in our explanations. For this reason, I distinguish weak well-foundedness and strong well-foundedness. Grounding might be weakly well-founded, even in case of an infinite regress of its grounds, but in such case, it cannot be strongly well-founded. Appealing to essences, however, can stop the regress entirely and make grounding strongly well-founded. Therefore, there is a strategic reason to postulate essences as grounds for grounding.

7 For such alternative account of grounding necessitarianism see: (O’Conaill, 2018; Rosen, 2010; Trogdon, 2013a).
} 
then $\alpha$ has $\Psi$ in every possible world where $\alpha$ exists) and unshareable (a given individual essence $\Psi$ can be possessed only by individual $\alpha$ with respect to all possible worlds) (Plantinga, 1979; Mackie, 2006; Roca-Royes, 2011). Necessity makes them essences, and unshareability makes them individual. From these two features, it follows that individual essence provides necessary criteria of the individuation of its possessor. ${ }^{8}$ In other words, two individuals necessarily cannot possess the same individual essence. Individual essence explains what it is to be a given individual rather than another one; thus, an individual essence cannot be shared among distinct entities. Therefore, individual essences obey the Principle of Identity of Indiscernibles (PII) (Adams, 1979; Hawley, 2009; Rodriguez-Pereyra, 2014):

$P I I_{I E}$ : For every $x$ and $y, x$ and $y$ are identical if they possess the same individual essence.

From here the notion of individual essence can be applied to grounding. Firstly, since I have assumed that grounding holds between facts, and given that we accept the ground-essence link, we can infer that if grounding holds, it holds in virtue of the individual essences of the facts that it connects. ${ }^{9}$ Here I assume that facts have essential properties and individual essences composed from these properties. I see no reason not to extend the notion of individual essence and to apply it to other ontological categories besides individuals, such as properties, propositions, states of affairs, or facts. Given that these entities have some properties (which seems to be trivially true), it seems natural for some among these properties to be essential and others to be accidental. Moreover, it is also natural to investigate what individuates these kinds of entities. If there are distinct properties, propositions, states of affairs, or facts, there must be something that explains why they are distinct; i.e., there has to be some principle of individuation that explains their distinctness. In what follows, I propose to take individual essences, understood as collections of essential properties, to be such individuators. However, note that if among the above-mentioned ontological categories only facts have individual essences, my argument would still work.

With respect to the notion of individual essence of facts, we might wonder: what does it take for a fact to have an individual essence at all?

As mentioned earlier, to define the individual essence of an entity $e$ is to explain what it is to be $e$ rather than any entity distinct from $e, e^{*}$; that is, what is the unique individuator of $e$. Applying this observation to the domain of facts, we can claim that individual essence $\Psi$ of any fact $f$ should explain what it takes to be $f$ rather than any other fact distinct from $f$. Thus, the individual essence of a given fact $f$ is its principle of individuation. Recall that a key assumption in this

\footnotetext{
${ }^{8}$ In that respect, the introduced notion of individual essence might seem very similar to the notion of constitutive essence provided by Fine (1994, 1995a, b). However, for this article, I utilize the concept of individual essence and will not discuss the similarities and differences between both notions.

9 The idea that grounding holds in virtue of essences of facts has been already recognized in a recent literature on grounding (Carnino, 2015); however, such a view has not been fully analysed and developed yet.
} 
article is that facts can be identified with true structured propositions. It is widely recognized (assuming that propositions are structured) that propositions are individuated by their constituents. Analogically, we could use such an observation in defining individual essences of facts:

Individual essence of fact: Necessarily, for any fact $f$, for $f$ to have individual essence $\Psi$ is to possess a collection of its constituents.

For example, the individual essence of a fact [Mary is a teacher] consists of an individual Mary and a property being a teacher. However, one might argue that two facts could differ even though they have the same constitutive elements. The argument runs as follows: Suppose that in possible world $w_{1}$, Mary is a teacher of John, and such a fact is called $\left[f_{1}\right]$. However, in possible world $w_{2}$, it is the case that John is a teacher of Mary, and such a fact is called $\left[f_{2}\right]$. Now, given the individual essence of fact principle, one might argue that since both $\left[f_{1}\right]$ and $\left[f_{2}\right]$ have the same constituents, they therefore have the same individual essences and (given the $\mathrm{PII}_{\mathrm{IE}}$ ) are identical. This would be absurd since we have a strong intuition that $\left[f_{1}\right]$ and $\left[f_{2}\right]$ are distinct facts.

My response: I cannot deny $\mathrm{PII}_{\mathrm{IE}}$ as it does seem to be a plausible principle (as long as one accepts the notion of individual essences at all). Therefore, the attention must be focused on the characterisation of individual essence of fact. It would seem that exact constituents alone are not sufficient to individuate facts. One would have to make a stronger claim and say that the individual essence of a given fact $f$ consists of having certain constituents ordered in a particular way. Applying this to the introduced example, it can be argued that the individual essences of $\left[f_{1}\right]$ and $\left[f_{2}\right]$ differ because they involve a specific order concerning individuals and properties instantiated by these individuals. For example, the individual essence of $\left[f_{1}\right]$ consists of having Mary, John and the property being a teacher exemplified by Mary as its constituents. In turn, the individual essence of $\left[f_{2}\right]$ consists of having Mary, John and the property of being a teacher instead exemplified by John as its constituents. These two individual essences differ because there is an ontological difference depending on who exemplifies the property of being a teacher. As a result, the individual essence of facts should be reformulated with a claim that:

Individual essence of fact*: Necessarily, for any fact $f$, for $f$ to have individual essence $\Psi$

is to possess a collection of its constituents ordered in some particular way.

As a result, facts cannot change their internal structure without losing their identity conditions. This will be crucial in my argument against contingentism. Before providing it however, let me explicate a last preliminary issue: what it means for grounding to hold in virtue of the individual essences of facts.

Accepting that facts have individual essences enables a modified version of the ground-essence link:

Ground-individual essence link: If $[\Phi]$ grounds $[f]$, then $[\Phi]$ grounds $[f]$ in virtue of the individual essence of $[\Phi]$ and the individual essence of $[f]$. 
My proposed account differs in at least two ways from the Finean conception of the relationship between grounding and essence. According to Fine (2012: 74-76), grounding relation is explained as holding in virtue of the nature of a derivative fact only. For instance, suppose that [Socrates is a human being] fully grounds [Socrates is rational]. According to the Finean view, this grounding relationship holds in virtue of a general essentialist truth that indicates an explanatory link between being human and being rational. A proponent of the Finean account could argue that [Socrates is a human being] grounds [Socrates is rational] because it lies in a nature of being rational that something can exemplify this property if and only if it exemplifies a property of being human.

In contrast, I claim that each grounding relation holds in virtue of the individual essence of grounding base (strictly speaking, the individual essence of each fact is included in the plurality of facts that constitute a grounding base; for simplicity I assume that grounding base is singular) as well as the individual essence of derivative fact. A further difference between our accounts is that I postulate individual essences rather than natures of facts (or natures of entities involved in facts). As I indicated earlier, individual essences provide identity conditions for facts; that is, they explain what it takes to be this particular fact rather than that particular fact. Thus, the concept of individual essence is much thinner than the original concept of nature proposed by Fine. Individual essences explain why grounding holds, not in virtue of some deep explanatory connections that hold between relata of grounding (or entities included in the relata), but merely in virtue of identities of the relata which are in turn determined by individual essences. Moreover, identities of both relata are relevant for answering the question of why a given grounding relation holds. On this view, any change in the identities of any relata of a particular grounding relation would entail a change of grounding relation itself. This claim is equivalent to a view that grounding relation is an internal relation whose identity is determined by identities of its relata. ${ }^{10}$

One might object that according to the individual essences of fact* principle, the individual essence of a given fact does not determine its relations to other facts, including grounding, causal, or ontological dependence relations. This is so because the individual essences of fact ${ }^{*}$ focuses only on internal structure of facts. Thus, by an appeal to the individual essence of fact* principle, one cannot successfully justify the idea that grounding relations hold in virtue of individual essences of their relata.

In response to this objection, I contend that the individual essences of facts are capable of determining patterns of metaphysical dependence relations between facts. It seems intuitive to claim that if some facts $\left[f_{1}\right]$ and $\left[f_{2}\right]$ remain in metaphysical dependence relations, then these relations are important for what these facts essentially are. For example, part of what it takes to be a fact [Socrates is conscious] is that it is grounded in some other, more fundamental fact(s) - for example, in facts about Socrates's brain (if we take physicalism to be true) - or that its obtaining makes some ethical or law facts obtain. This however does not

\footnotetext{
${ }^{10}$ For the discussion of the view that grounding is an internal relation see: Correia (2005); deRosset (2013a); Leuenberger (2014); Bennett (2017).
} 
entail that individual essences explain the exact nature of these relationships between facts. Instead, individual essences merely indicate that if a given fact stays in some particular relations of metaphysical dependence to other facts, they do so by virtue of their respective individual essences. Moreover, if any two facts stay in different relations of metaphysical dependence to some other facts, it is a reason to infer that two facts in question are distinct. In other words, for any facts $\left[f_{1}\right]$ and $\left[f_{2}\right]$, if $\left[f_{1}\right]$ stays to other facts in different explanatory relations (including grounding relations) than $\left[f_{2}\right]$ does, then necessarily $\left[f_{1}\right] \neq\left[f_{2}\right]$. But how can we know that facts $\left[f_{1}\right]$ and $\left[f_{2}\right]$ stay in different grounding relations to other facts? We cannot derive such knowledge from our knowledge of their respective individual essences because this would entail that individual essences are explanatory in the sense associated with Finean natures. But no matter the source of these differences and our knowledge about them, if there are such differences between facts, these differences entail the numerical distinctness of facts.

If we accept the view that identities of facts are determined by their respective individual essences and if part of what it is to be a given fact is to be in such-andsuch relations of metaphysical dependence to other facts, then individual essence of fact ${ }^{*}$ should be further modified to cover relational aspects of facts. Thus, we could propose the following modification:

Individual essence of fact ${ }^{* *}$ : Necessarily, for any fact $f$, for $f$ to have individual essence $\Psi$

is to (a) possess a collection of its constituents ordered in some particular way and (b) be in some particular relationships of metaphysical dependence to other facts.

Equipped with such understanding of individual essences of facts, we can reconsider ground-individual essence link. According to this principle, a given grounding relation $G$ holds between $[\Phi]$ and $[f]$ in virtue of individual essences of both relata. Most importantly, the ground-individual essence link principle implies that any modification of individual essences of the relata of $G$ would undermine that grounding relation $G$ holds for $[\Phi]$ and $[f]$. In cases where $[\Phi]$ grounds $[f]$ in virtue of individual essence $\Psi$ of $[f]$ and individual essence $\Gamma$ of $[\Phi]$, then one could modify the individual essence of $[\Phi]$. E.g., [ $\Phi]$ could be modified by changing constitutive facts or by changing its relationships of metaphysical dependence to other facts. In these cases, one would replace $[\Phi]$ with a distinct plurality of facts $\left[\Phi^{*}\right]$. However, modifying $[\Phi]$ in such ways would not entail that $[\Phi]$ does not necessitate $[f]$ (as it is posited by contingentists). Instead, it would indicate that some new plurality of facts $\left[\Phi^{*}\right]$ (where $[\Phi] \neq\left[\Phi^{*}\right]$ ) grounds (or does not ground) [f]. However, if a derivative fact $[f]$ is individuated (partially) by its relation to a grounding base $[\Phi]$, and a grounding base $[\Phi]$ is replaced by $\left[\Phi^{*}\right],[f]$ would not obtain either since $[f]$ would have changed its individual essence, and it should be replaced with $\left[f^{*}\right]$ (where $[f] \neq\left[f^{*}\right]$ ). As a result, by changing the individual essence of $[\Phi]$, one also changes the subject from an initial grounding relation $G$ wherein $[\Phi]$ grounds $[f]$ to a distinct grounding relation $G^{*}$ that might take the form of $\left[\Phi^{*}\right]$ grounds $\left[f^{*}\right]$ or that $\left[\Phi^{*}\right]$ does not ground $\left[f^{*}\right]$. 
Now, let me apply these remarks to the discussion of the contingentist's argument from the restricted accidental generalisation against grounding necessitarianism.

\section{Against the Argument from Restricted Accidental Generalisations}

The argument from restricted accidental generalisations is problematic for the grounding necessitarianist only if she accepts principle (2), according to which:

(2) Restricted accidental generalisations are fully grounded in their instances.

In defending her position, a proponent of grounding necessitarianism might be tempted to deny this principle and claim that generalisations are grounded in something other than their instances (e.g., in laws of nature or dispositions). But such approach is undesirable because it disregards the strong intuition that instances of generalisations play an important role in explaining generalisations. Fortunately, a less revisionary approach is available. Instead of denying that instances play an important role in explaining generalisations, I suggest modifying principle (2) to the claim that instances provide only partial grounds for generalisations. With this modification, I preserve an intuition about the importance of instances in explaining generalisations while also making room for additional grounds for generalisations that (when coupled with instances) might fully ground them.

In the literature we can find two accounts of what are the further grounds for restricted accidental generalisations: one that appeals to the notion of restricted totality fact ${ }^{11}$ and one that appeals to essences. ${ }^{12}$ Below I provide a variant of the second strategy of answering the contingentist's objection. This strategy relies on my previous investigations concerning individual essences and their relation to grounding in general. According to my proposal, restricted accidental generalisations are grounded in their instances (pace principle 2) and in the individual essences of these instances as well as individual essence of a given restricted accidental generalisation (which follows from the ground-individual essence link principle). I return to my earlier example with swans in order to explain further:

\footnotetext{
11 Usually a restricted totality fact is conceived as having the logical form [V $x(F x \rightarrow(x=a \vee x=b \vee$ $\ldots)$ )], where $a, b$, etc. are the only things that are $F$ (Armstrong, 1997; Skiles, 2015: 733; McDaniel, 2017: 180-181). It is a totality fact because it states that there are only such-and-such individuals with such-and-such properties. It is restricted because it ranges over a restricted domain of individuals and properties (e.g., white swans in Switzerland). According to Gideon Rosen, restricted totality facts (coupled with instances of restricted accidental generalisations) ground restricted accidental generalisations. The idea is to interpret $[Q]$ as a fact according to which $\left[a_{1} \& a_{2} \& a_{3}\right]$ coupled with a totality fact [t] according to which facts $\left[a_{1}\right] \&\left[a_{2}\right] \&\left[a_{3}\right]$ are all the relevant facts about swans. According to this view, a possibility of $\left[Q^{*}\right]$ is unproblematic, for if [Q*] is read as a conjunctive fact $\left[a_{1} \& a_{2} \& a_{3} \& a_{4}\right]$ coupled with a respective totality fact $\left[t^{*}\right]$ according to which facts $\left[a_{1}\right] \&\left[a_{2}\right] \&\left[a_{3}\right] \&\left[a_{4}\right]$ are all the relevant facts about swans, then at $\mathrm{w}_{\mathrm{x}}\left[Q^{*}\right]$ cannot coexist with $[Q]$. Thus, a problematic scenario for a necessitarianism disappears. However, the whole solution hinges on the notion of a restricted totality fact, which is often claimed to be problematic. For a discussion see: (Carnino, 2015; Skiles, 2015).

12 Some variants of this strategy can be found in Rosen (2010) and O'Conaill (2018).
} 
First, consider the grounding base $[Q]$. According to it, $a_{1}$ is white and in Switzerland \& $a_{2}$ is white and in Switzerland \& $a_{3}$ is white and in Switzerland. In short: $\left[a_{1} \& a_{2} \& a_{3}\right]$. Now, to be (partially) an individual essence $\Psi_{\mathrm{Q}}$ of $[Q]$ is for $[Q]$ it to contain swans $a_{1}, a_{2}, a_{3}$. However, as it follows from individual essence of fact ${ }^{*} *$ principle, $\Psi_{\mathrm{Q}}$ also determines grounding relations in which $[Q]$ might stay. More specifically, to be an individual essence $\Psi_{\mathrm{Q}}$ of $[Q]$ is for $[Q]$ to be such that in every possible world in which $[Q]$ obtains, it grounds $[p]$. There is no possible world in which $[Q]$ obtains but does not ground $[p]$.

Analogical remarks hold for a derivative fact $[p]$ according to which all swans in Switzerland are white. To be (partially) an individual essence $\Gamma_{\mathrm{p}}$ of $[p]$ is for $[p]$ to be grounded in a conjunctive fact $[Q]$, according to which $a_{1}$ is white and in Switzerland \& $a_{2}$ is white and in Switzerland \& $a_{3}$ is white and in Switzerland. That is, for $[p]$ to preserve its individual essence $\Gamma_{\mathrm{p}}$ and be $[p]$, is to be grounded in $[Q]$ in every possible world in which $[p]$ obtains. ${ }^{13}$

With this in mind, reconsider possible world $w_{x}$ in which someone smuggled a black swan from Poland to Switzerland. We will call this swan $a_{4}$. In such possible world, in addition to facts $\left[a_{1}\right],\left[a_{2}\right]$ and $\left[a_{3}\right]$ there is fact $\left[a_{4}\right]$, according to which $a_{4}$ is a black swan in Switzerland. All four facts grouped together give rise to new conjunctive fact $\left[Q^{*}\right]$. Now, since $[Q]$ has different constituents than $\left[Q^{*}\right]$ it follows that they are distinct. Moreover, a further difference between both facts lies in a fact that $[Q]$ stays in distinct grounding relations than $\left[Q^{*}\right]$ does. While $[Q]$ grounds $[p]$, $\left[Q^{*}\right]$ does not ground $[p]$ because $\left[Q^{*}\right]$ contains the fact that there is black swan in Switzerland. This fact is incompatible with the fact that all swans in Switzerland are white.

At this point a contigentist might interrupt and claim that since $[Q]$ obtains at $w_{x}$ but does not ground $[p]$ there due to $\left[\mathrm{Q}^{*}\right]$ obtaining at $w_{x}$, grounding necessitarianism cannot be true.

In response, I claim that if $[Q]$ does not ground $[p]$ it cannot obtain at $w_{x}$ because part of an individual essence $\Psi_{\mathrm{Q}}$ is that $[Q]$ grounds $[p]$. If $[Q]$ does not ground $[p]$ at $w_{x}$, it entails a change within a character of $\Psi_{\mathrm{Q}}$ which in turn entails a change of identity of $[Q]$ as well. For this reason and contrary to the contingentist account, I claim that $[Q]$ cannot obtain at $w_{x}$.

Now, if $[Q]$ is absent from $w_{x}$ and $\left[Q^{*}\right]$ does not ground $[p]$ and it is part of $\Gamma_{\mathrm{p}}$ that $[p]$ is grounded in $[Q]$ (as I indicated above), then in order to avoid a consequence that $[p]$ turns out to be fundamental (ungrounded) or primitive, we must claim that $[p]$ is absent from $w_{x}$ as well. Asa result, neither $[Q]$ nor $[p]$ obtain at $w_{x}$. This conclusion, contrary to what contingentists claim, does not pose any problems for the initial claim that $[Q]$ necessitates $[p]$. According to

\footnotetext{
13 When I say that it lies in the individual essence of $[p]$ that $[p]$ has such-and-such constituents and that $[p]$ is grounded in $[Q]$, it does not entail that $[Q]$ explains $[p]$ in a Finean sense of explanation that appeals to a notion of general essentialist explanation. My proposed account states merely that in order for $[p]$ to be $[p]$ it has to preserve its constituents and it can preserve them only if it preserves its particular grounding relationship to $[Q]$.
} 
necessitarianism, $[Q]$ necessitates $[p]$ only if both facts obtain. ${ }^{14}$ Now, if both $[Q]$ and $[p]$ are absent from $w_{x}$, it follows that what takes place at $w_{x}$ is completely irrelevant for a status of initial grounding relation holding between $[Q]$ and $[p]$. Thus, grounding necessitarianism can be defended against a contingentist argument.

Taking this into account, it seems that the real issue is whether I can maintain a claim that $[Q]$ does not obtain at $w_{x}$. A contingentist might deny this by observing that if conjunctions (or conjunctive facts) are fully grounded in their conjuncts it follows that $[Q]$ can co-obtain with $\left[Q^{*}\right]$ at $w_{x}$. But $[Q]$ does not ground $[p]$ in this case because $\left[Q^{*}\right]$ precludes that $[Q]$ grounds $[p]$. As a consequence, all three facts obtain at $w_{x}$, yet $[Q]$ does not ground $[p]$. Thus, grounding necessitarianism is false.

I have two responses to this:

Firstly, even if it is true that $[Q]$ can co-obtain with $\left[Q^{*}\right]$ at $w_{x},[p]$ does not obtain at $w_{x}$ for $\left[Q^{*}\right]$ precludes $[p]$ obtaining there. In effect, the contingentist cannot establish the desired consequence that both $[Q]$ and $[p]$ obtain at $w_{x}$, yet $[Q]$ does not ground $[p]$. If there is no $[p]$ at $w_{x}$, there is no problem for necessitarianism. But why claim that $[p]$ is absent from $w_{x}$ ? Well, if at $w_{x}$ there are four swans in Switzerland and only three of them are white but a fourth one is black (which is what $\left[Q^{*}\right]$ states), it trivially follows that not all swans in Switzerland are white at $w_{x}$. In other words, it is not the case that $[p]$. There is simply no such generalisation at $w_{x}$.

Secondly, I argue that not only $[p]$ is absent from $w_{x}$ but $[Q]$ is absent as well. While one could deny that conjunctions are grounded in their conjuncts this would be a highly unorthodox move. Instead, I argue that all relevant facts about swans - as well as generalisations themselves - should be read as world-indexed facts. ${ }^{15}$ According to my idea, there are no facts about swans simpliciter but each particular fact about each swan should be interpreted as relativized to a possible world in which it obtains. By applying this view to the presented argument, facts about particular swans in Switzerland (in the actual world), instead of being $\left[a_{1}\right]$, $\left[a_{2}\right]$ and $\left[a_{3}\right]$, should be read as $\left[a_{1}\right.$ at $\left.w_{@}\right],\left[a_{2}\right.$ at $\left.w_{@}\right]$, and $\left[a_{3}\right.$ at $\left.w_{@}\right]$. These facts are then distinguishable from their counterparts at $w_{x}$ (coupled with a fact about black swan $a_{4}$ ) that take a form of: $\left[a_{1}\right.$ at $\left.w_{x}\right],\left[a_{2}\right.$ at $\left.w_{x}\right],\left[a_{3}\right.$ at $\left.w_{x}\right]$ and $\left[a_{4}\right.$ at $\left.w_{x}\right]$. These are two different pluralities of facts that give rise to two distinct conjunctive facts $\left[Q\right.$ at $\left.w_{@}\right]$ and $\left[Q\right.$ at $\left.w_{x}\right]$ which are both world-indexed. Both of these conjunctive facts have different constituents and they remain in different grounding relations. Most importantly, since at $w_{x}$ there are no $\left[a_{1}\right.$ at $\left.w_{@}\right],\left[a_{2}\right.$ at $\left.w_{@}\right]$ and $\left[a_{3}\right.$ at $\left.w_{@}\right]$, but only their counterparts, it follows that at $w_{x}$ there are no $\left[Q\right.$ at $\left.w_{@}\right]$ either. Given this, I maintain a view that neither $[p]$ nor $[Q]$ (taken as $\left[Q\right.$ at $\left.w_{@}\right]$ ) obtain at $w_{x}$.

\footnotetext{
14 This presuppose that grounding is factive. According to factivity thesis, if $[\Phi]$ grounds $[f]$ both $[\Phi]$ and $[f]$ obtain. For more details on factivity of grounding see: (Fine, 2015; Raven, 2015; Rosen, 2010). It seems that such presumption is unproblematic both for contingentists and necessitarianists.

15 That said, I would like to remain neutral on the issue of whether all facts as such should be taken as world-indexed.
} 


\section{Some Objections}

For the remainder of this paper, I will address some possible objections to my proposal.

First objection: Someone might argue that if essences are necessary elements of being (which is a common assumption), then essences exist in every possible world, and equivalently, facts about essences obtain in every possible world. Now, if such essences (or facts about them) would ground (necessitate) restricted accidental generalisations, this would entail that restricted accidental generalisations obtain in every possible world in which essences obtain; that is, literarily in every possible world. Such a consequence, however, seems to contradict the spirit of restricted accidental generalisations as such, which are meant to be accidental rather than necessary.

Reply: A possible solution to this argument is to claim that individual essences are specific kinds of essences which, even though necessary, are not exemplified in all possible worlds. For example, an individual essence of fact [Someone being Sherlock Holmes] exists at all possible worlds, yet it does not obtain at all possible worlds, e.g. [Someone being Sherlock Holmes] does not obtain at the actual world for it is not true about any actually existing human being. Another option is to argue that individual essences ontologically depend on the existence of their exemplifications. Thus, if there is no existing individual that is characterised by a fact [Someone being Sherlock Holmes], then there is no individual essence of [Someone being Sherlock Holmes] either; that is, there is no such fact as [Someone being Sherlock Holmes] at all, because this fact and its individual essence ontologically depend on the existence of an individual that is part of such fact and, a fortiori, of its individual essence. Regardless of which approach towards individual essences we prefer, each is capable of providing an account of contingency of restricted accidental generalisations within the essentialist framework.

Second objection: A contingentist might argue against the conception of worldindexed facts by claiming that such conception of facts has the consequence that one and the same restricted accidental generalisation cannot be grounded in wholly disjointed sets of its instances. For example, it entails that there are no distinct possible worlds that contain two wholly disjoint sets of white swans and that contain the same accidental generalisation [All swans are white]. This, however, seems to be controversial because it follows from generality of restricted accidental generalisations that they can be true at more than one possible world.

Reply: I agree that my view has such a consequence but I do not agree that this is a reason for us to abandon it. Instead, I claim that generality of restricted accidental generalisations has nothing to do with modality (that is, with a range of possible worlds at which a given generalisation is true). Restricted accidental generalisations are general in the sense that they are quantifications over many individual objects. And of course, my view is consistent with that claim. The indexical analysis of restricted accidental generalisations explicates not their generality but their accidentality. According to my view, generalisations are accidental in the sense that they are never true in more than one possible world. For 
example, if we suppose that [All cats in Poland are black] and claim that at possible world $w_{x}$ [All cats in Poland are black] also obtains, it is not the case that one and the same generalisation obtains at two possible worlds, but rather that there are two very similar yet numerically distinct world-indexed generalisations: [All cats in Poland are black at $w_{@}$ ], which obtains at $w_{@}$, and [All cats in Poland are black at $w_{x}$ ], which obtains at $w_{x}$.

Someone unconvinced by the above reply could claim that restricted accidental generalisations are accidental in the sense that they obtain in some rather than all possible worlds. This claim opens up the possibility that a given restricted accidental generalisation could be grounded in disjointed sets of its instances at distinct possible worlds.

In response, I deny that one and the same fact can obtain in more than one possible world because all world-indexed facts are worldbound. However, in order to preserve an intuition that one and the same generalisation could obtain at more than one possible world, I could adopt a counterpart theory for facts themselves and claim that a given restricted accidental generalisation could obtain at distinct possible world in virtue of having counterparts at relevant possible worlds that obtain there. For example, a fact [All swans in Switzerland are white at $w_{@}$ ] could obtain at $w_{x}$ in virtue of having at $\mathrm{w}_{\mathrm{x}}$ a counterpart, namely a fact [All swans in Switzerland are white at $w_{x}$ ] which obtains there. Due to space limitations, I cannot offer details here. At this point it is sufficient to show that I can use some theoretical tools which could make my view compatible with an intuition about accidental nature of restricted accidental generalisations.

Third objection: One might argue that the cost of my approach towards identity conditions of facts suggested by the individual essence of fact** principle coupled with indexical analysis of facts is an overabundance of facts, for any change in constituents, order, or their relationships to other facts or worlds gives rise to a new fact.

Reply: I see no problem with such a plenitude of facts. It seems that as long as our attention is restricted to individual essences of facts only, there is no non-arbitrary principle that would restrict how many facts there are or could have been. This holds as long as we do not postulate that despite individual essences facts also have some general essences, such as kind properties, that would allow for facts to change at least some of their constituents or relational features without losing identity conditions provided by their respective general essences. Yet it is unclear to me what such essences of facts would look like. For example, suppose that such a general essence of fact were the property being derivative. Next, suppose that fact [All swans are white] is an essentially derivative fact. It would entail that this fact could change some of its features, but as long as it preserves its essence being a derivative fact, it is one and the same fact. This would open up a possibility that [All swans are white] could exist at different possible worlds. However, this is problematic for a proponent of grounding necessitarianism because it allows for facts having different grounds at distinct possible worlds. Thus, the conception of general essences of facts seems to presuppose falsity of grounding necessitarianism. This, however, begs the question (at least within the scope of the current discussion) because in order to make sense of the objection towards plenitude of facts postulated by grounding necessitarianism 
we have to already presuppose the falsity of necessitarianism. This is a reason for which a necessitarianist should be suspicious that facts have general essences.

\section{Concluding Remarks}

In this paper, I have argued that the contingentists' recent argument from restricted accidental generalisations against grounding necessitarianism is not successful in undermining necessitarianism. In defending my position, I have appealed to the idea that grounding holds in virtue of the essences of its relata. What was new about my approach was my introduction of a specific kind of essences - individual essences - that explain necessity of grounding. I have described what individual essences are, how they can be related to facts, and how to understand a claim that grounding holds in virtue of the individual essences of its relata. Following that, I argued that if someone accepts a view that facts are individuated by their respective individual essences, then she has resources to resist the argument from restricted accidental generalisations.

Acknowledgements I would like to thank Marek Gurba, Sebastian Kołodziejczyk, Szymon Mazurkiewicz, Paweł Rojek and Artur Szachniewicz for their helpful comments on earlier drafts of this paper.

Funding This publication was generously supported by a grant from the National Science Center, Poland, No. 2013/11/D/HS1/04332.

Data Availability Not applicable.

Code Availability Not applicable.

Declarations

Conflicts of Interest/Competing Interests Not applicable.

Open Access This article is licensed under a Creative Commons Attribution 4.0 International License, which permits use, sharing, adaptation, distribution and reproduction in any medium or format, as long as you give appropriate credit to the original author(s) and the source, provide a link to the Creative Commons licence, and indicate if changes were made. The images or other third party material in this article are included in the article's Creative Commons licence, unless indicated otherwise in a credit line to the material. If material is not included in the article's Creative Commons licence and your intended use is not permitted by statutory regulation or exceeds the permitted use, you will need to obtain permission directly from the copyright holder. To view a copy of this licence, visit http://creativecommons.org/licen ses/by/4.0/.

\section{References}

Adams, R. M. (1979). Primitive thisness and primitive identity. The Journal of Philosophy, 76(1), 5-26.

Armstrong, D. M. (1997). A world of states of affairs. Cambridge University Press.

Audi, P. (2012). A clarification and defense of the notion of grounding. In: F. Correia, \& B. Schnieder (Eds.), Metaphysical grounding: Understanding the structure of reality (pp. 101-122). Cambridge University Press.

Bennett, K. (2011). By Our Bootstraps. Philosophical Perspectives, 25(1), 27-41.

Bennett, K. (2017). Making things up. Oxford University Press. 
Carnino, P. (2015). On the reduction of grounding to essence. Studia Philosophica Estonica, 7(2), 56-71.

Chudnoff, E. (manuscript) Grounding and entailment.

Correia, F. (2005). Existential dependence and cognate notions. Philosophia.

Correia, F. (2013). Metaphysical Grounds and Essence. In: M. Hoeltje, B. Schnieder, \& A. Steinberg (Eds.), Varieties of dependence. Basic philosophical concepts (pp. 271-296). Philosophia Verlag.

Correia, F., \& Skiles, A. (2019). Grounding, essence, and identity. Philosophy and Phenomenological Research, 98(3), 642-670.

Dancy, J. (2004). Ethics without principles. Clarendon Press.

Dasgupta, S. (2014a). On the plurality of grounds. Philosopher's Imprint,14(20), 1-28.

Dasgupta, S. (2014b). The possibility of physicalism. The Journal of Philosophy, 111(9/10), 557-592.

deRosset, L. (2013a). Grounding explanations. Philosopher's. Imprint, 13(7), 1-26.

deRosset, L. (2013b). No free lunch. In: M. Hoeltje, B. Schnieder, \& A. Steinberg (Eds.), Varieties of dependence. Basic philosophical concepts (pp. 243-270). Philosophia Verlag.

Dixon, S. (2016). What is the well-foundedness of grounding? Mind, 125(498), 439-468.

Fine, K. (1994). Essence and modality. Philosophical Perspectives, 8, 1-16.

Fine, K. (1995a). Ontological dependence. Proceedings of the Aristotelian society, 95(1995), 269-290.

Fine, K. (1995b). Senses of essence. In: W. Sinnott-Armstrong, D. Raffman, \& N. Asher (Eds.), Modality, Morality, and Belief: Essays in Honor of Ruth Barcan Marcus (pp. 55-73). Cambridge University Press.

Fine, K. (2012). Guide to ground. In: F. Correia, \& B. Schnieder (Eds.), Metaphysical grounding: Understanding the structure of reality (pp. 37-80). University Press.

Fine, K. (2015). Unified foundations for essence and ground. Journal of the American Philosophical Association, 1(2), 296-311.

Hawley, K. (2009). Identity and indiscernibility. Mind, 118(469), 101-119.

King, J. (2007). The nature and structure of content. . Oxford University Press.

King, J. (2009). XIII-Questions of Unity. Proceedings of the Aristotelian Society, Vol. CIX, Part 3, 257-277.

Leuenberger, S. (2014). Grounding and necessity. Inquiry, 57, 151-174.

Mackie, P. (2006). How things might have been: Individuals, kinds, and essential properties. Oxford University Press.

McDaniel, B. (2017). Grounding and the objection from accidental generalizations. Thought: A Journal of Philosophy, 6(3), 178-184.

O'Conaill, D. (2018). Grounding, physicalism and necessity. Inquiry, 67(7), 713-730.

Plantinga, A. (1979). De essentia. Grazer PhilosophischeStudien, 7, 101-121.

Rabin, G. O., \& Rabern, B. (2016). Well founding grounding grounding. Journal of Philosophical Logic, 45(4), 349-379.

Raven, M. (2015). Ground. Philosophy Compass, 10(5), 322-333.

Roca-Royes, S. (2011). Essential properties and individual essences. Philosophy Compass, 6(1), 65-77.

Rodriguez-Pereyra, G. (2014). Leibniz's Principle of Identity of Indiscernibles. OUP Oxford.

Rosen, G. (2010). Metaphysical Dependence: Grounding and Reduction. In: B. Hale, \& A. Hoffman (Eds.), Modality: Metaphysics, Logic, and Epistemology (pp. 109-136). Oxford University Press.

Schaffer, J. (2010). Monism: The priority of the whole. Philosophical Review, 119(1), 31-76.

Schnieder, B. (2016). A certain kind of trinity: Dependence, substance, and explanation. Philosophical Studies, 129, 393-419.

Skiles, A. (2015). Against grounding necessitarianism. Erkenntnis, 80(4), 717-751.

Soames, S. (2010). What is meaning? . Princeton University Press.

Trogdon, K. (2013a). Grounding: Necessary or contingent? Pacific Philosophical Quarterly, 94, 465-485.

Trogdon, K. (2013b). An introduction to grounding In: M. Hoeltje, B. Schnieder, \& A. Steinberg (Eds.), Varieties of dependence. Basic philosophical concepts (pp. 97-122). Philosophia Verlag.

Publisher's Note Springer Nature remains neutral with regard to jurisdictional claims in published maps and institutional affiliations. 